\title{
Translation Elongation by Rotation in a Still Fluid of a Solid Cone with a Spiral Vane
}

\author{
Kern E. Kenyon \\ North Lane, Del Mar, USA \\ Correspondence to: Kern E. Kenyon, kernken@aol.com \\ Keywords: Rotation, Translation, Elongation \\ Received: October 21, $2021 \quad$ Accepted: December 5, $2021 \quad$ Published: December 8, 2021 \\ Copyright (c) 2021 by author(s) and Scientific Research Publishing Inc. \\ This work is licensed under the Creative Commons Attribution International License (CC BY 4.0). \\ http://creativecommons.org/licenses/by/4.0/

\section{(c) (i) Open Access}

\section{ABSTRACT}

Within the field of physics, the idea of perpetual motion is not allowed in most references. However, in a still fluid, one potential perpetual motion example is offered: a hollow solid cone rotating about its long axis at a constant rate.

\section{INTRODUCTION}

An amazing and unusual mechanical concept is the hollow solid cone rotating under still water about its long axis at a constant rate [1]. Theory predicts the cone will translate down the long axis, base first and apex last [2]. Some existing observations support the theory [1]. It is self-evident from the theory that the greater the given constant rotation rate is, the larger is the driving force for the translation [3].

Where the concept leads is partially explored next.

\section{ARGUMENT}

For example, if while rotating and translating a rigid spiral vane somehow pops up into place on the cone's outside surface, attached vertically to it. By interacting with the motion of the translation, the rotation rate will increase, then the translation rate will correspondingly increase. How could this sequence of events not result in a run-away system: enhanced rotation produces enhanced translation and increased translation makes increased rotation? Or in other words, a type of perpetual motion?

A situation with a sudden popping up on the cone's outside surface of the rigid spiral vane is brought in from nature: the cone shaped egg case of the North Pacific horn shark [3]. That must involve a chemi$\mathrm{cal} /$ biological/physical process of some kind which only takes a day or two to complete after birth in saltwater of the egg. A guess at the evolutionary development and how it benefits the shark's life cycle has been offered [3].

To imitate this biological spiral vane behavior ahead of time in a laboratory may occur as follows. Let the spiral vane initially lie flat and upside down, pinned vertically to the rotating translating cone's outside surface with equally spaced pins, the longer curved lines oriented up. When the loose edge of sinusoidal surface side of the spiral vane contacts the rotating flow heading toward it, the edge of the spiral could be 
lifted up and flung back [fanned out] thereby into a vertical grid positioned against the pins.

\section{CONCLUSION}

Until observations are available to compare with the theory, the main conclusion of the theory remains: a hollow rotating solid cone with a spiral vane will have an elongated translation that could become perpetual.

\section{ACKNOWLEDGEMENTS}

Phil Schneider and Doug Kenyon are thanked for comments.

\section{CONFLICTS OF INTEREST}

The author declares no conflicts of interest regarding the publication of this paper.

\section{REFERENCES}

1. Kenyon, K.E. (2020) Cone Rotating in a Fluid. Natural Science, 12, 1-3. https://doi.org/10.4236/ns.2020.121001

2. Kenyon, K.E. (2020) Nature's Translating Cone Rotating under Water Translates. European International Journal of Science and Technology, 9, 9-10.

3. Adachi, T., Takahashi, Y., Akinga, T. and Okajina, J. (2018) Effect of Viscosity on Pumping up of Newtonian Fluid Dnion by a Rotating Cone. Journal of Flow Control, Measurement and Visualization, 6, 57-65.

https://doi.org/10.4236/jfcmv.2018.62006 